\title{
Femoral head diameter in the Malaysian population
}

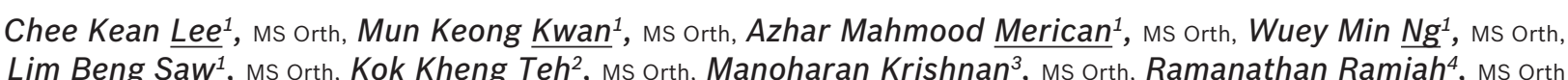

INTRODUCTION Hip arthroplasty is commonly performed worldwide. The objective of this study was to determine the diameter of the femoral head in the Malaysian population in relation to gender and race (i.e. among Malay, Chinese and Indian patients).

METHODS This was a retrospective cross-sectional study performed between January 1995 and December 2006, evaluating the femoral head diameters of all patients aged 50 years and above who underwent hemiarthroplasty at two major hospitals in Malaysia.

RESULTS A total of 945 femoral heads ( 663 women, 282 men) were evaluated. The mean age of the patients in our cohort was $75.2 \pm 9.4$ (range 50-101) years. The mean femoral head diameter (with intact articular cartilage) was $44.9 \pm 3.2$ (range 38-54) $\mathrm{mm}$. In our study, men had a significantly larger mean femoral head diameter than women $(47.7 \pm 2.8 \mathrm{~mm}$ vs. $43.7 \pm 2.4 \mathrm{~mm} ; \mathrm{p}<0.05)$. Patients of Chinese ethnicity were also found to have significantly larger femoral head diameters, when compared among the three races studied $(p<0.05)$.

CONCLUSION Malaysians have a mean femoral head diameter of $44.9 \pm 3.2 \mathrm{~mm}$. Among our patients, Chinese patients had a significantly larger femoral head size than Malay and Indian patients. We also found that, in our cohort, men had significantly larger femoral head diameters than women.

Keywords: Chinese, femoral head diameter, Indian, Malay, Malaysia

\section{INTRODUCTION}

Arthroplasty of the hip is one of the most commonly performed orthopaedic surgeries worldwide. ${ }^{(1,2)}$ Sizing of the femoral head is important for determining the appropriate size of implants to be used for a patient undergoing hip arthroplasty. ${ }^{(3)}$ However, the available data on the common sizes of implants used are mainly based on studies of Caucasian populations. ${ }^{(4-6)}$ The Caucasian morphometry is generally perceived to be larger than that of Asian populations. ${ }^{(7)}$ Given this, the aim of the present study was to determine the average size and distribution of femoral head diameter in a Malaysian population with respect to gender and race (i.e. among Malay, Chinese and Indian patients). We also compared our findings with that of previous studies in the English literature.

\section{METHODS}

This study was a retrospective cross-sectional study of 12-year duration performed from January 1995 to December 2006 at two major hospitals in Malaysia, evaluating the femoral heads of all patients aged 50 years and above who underwent hemiarthroplasty surgery, which was largely due to femoral neck fractures.

A standard lateral or posterior surgical approach to the hip was used in all patients. After capsulotomy of the hip, the femoral head was delivered out for measurement. The diameter of the femoral head was measured intraoperatively using standard fullcircular templates, with the surgeons passing the femoral head through the circular template, progressing from smaller rings to larger ones. The diameter of the femoral head was taken to be the ring size of the full-circular template that the femoral head was just able to pass through.

Patients with deformed femoral heads secondary to avascular necrosis and/or advanced arthritis were excluded from the study. Data was collected, tabulated and analysed using the Statistical Package for the Social Sciences (SPSS Inc, Chicago, IL, USA) and Primer of Biostatistics statistical software (McGraw-Hill, New York, NY, USA). Comparison of means was carried out using independent $t$-test, with statistical significance set at $\mathrm{p}<0.05$.

\section{RESULTS}

Our study comprised 945 femoral heads that were evaluated. In all, 663 (70.2\%) were women and 282 (29.8\%) were men (Table I). The majority of the patients in our cohort were Chinese ( $\mathrm{n}=612,64.8 \%)$, followed by Malays ( $\mathrm{n}=169,17.9 \%$ ) and Indians ( $\mathrm{n}=152,16.1 \%)$, with 12 (1.3\%) patients from other races. The mean age of the patients was 75.2 \pm 9.4 (range 50-101) years.

The mean femoral head diameter (with intact articular cartilage) among Malaysian patients in our study was found to be $44.9 \pm 3.2$ (range 38-54) mm (Table I). Men had significantly larger mean femoral head diameters than women $(47.7 \pm 2.8 \mathrm{~mm}$ vs. $43.7 \pm 2.4 \mathrm{~mm} ; \mathrm{p}<0.05)$. Among the three races evaluated, the mean femoral head diameter was largest in Chinese patients $(45.2 \pm 3.1 \mathrm{~mm})$, followed by Indian $(44.4 \pm 3.3 \mathrm{~mm})$ and Malay $(44.2 \pm 3.0 \mathrm{~mm})$ patients. The femoral head diameters in Chinese patients were significantly larger than those in Indian and Malay patients $(\mathrm{p}<0.05$; Table II). There was no statistically significant difference between the femoral head diameters in Indian and Malay patients $(p>0.05)$.

\footnotetext{
${ }^{1}$ Department of Orthopaedic Surgery, Faculty of Medicine, University of Malaya, Kuala Lumpur, ${ }^{2}$ Department of Orthopaedic Surgery, Hospital Ampang, ${ }^{3}$ Department of Orthopaedic Surgery, Hospital Taiping, ${ }^{4}$ Department of Orthopaedic Surgery, Hospital Ipoh, Perak, Malaysia

Correspondence: Dr Lee Chee Kean, Senior Lecturer, Department of Orthopaedic Surgery, Faculty of Medicine, University of Malaya, Kuala Lumpur 50603, Malaysia. kenetto@hotmail.com
} 
Table I. Femoral head diameters in Malaysian patients, stratified according to gender and race.

\begin{tabular}{|c|c|c|c|}
\hline \multirow[t]{2}{*}{ Variable } & \multirow{2}{*}{$\begin{array}{c}\text { No. of } \\
\text { patients }\end{array}$} & \multicolumn{2}{|c|}{ Femoral head diameter $(\mathrm{mm})$} \\
\hline & & Mean \pm SD (range) & Mode \\
\hline Total $(n=945)$ & & $44.9 \pm 3.2(38-54)$ & \\
\hline Men & 282 & $47.7 \pm 2.8(38-54)$ & 48 \\
\hline Women & 663 & $43.7 \pm 2.4(38-52)$ & 44 \\
\hline Chinese $(n=612)$ & & $45.2 \pm 3.1(38-54)$ & \\
\hline Men & 175 & $48.0 \pm 2.7(38-54)$ & 48 \\
\hline Women & 437 & $44.0 \pm 2.4(38-52)$ & 44 \\
\hline Malay $(n=169)$ & & $44.2 \pm 3.0(38-54)$ & \\
\hline Men & 44 & $47.4 \pm 3.1(41-54)$ & 48 \\
\hline Women & 125 & $43.0 \pm 2.0(38-50)$ & 44 \\
\hline Indian ( $\mathrm{n}=152$ ) & & $44.4 \pm 3.3(39-54)$ & \\
\hline Men & 58 & $47.0 \pm 2.7(40-54)$ & 48 \\
\hline Women & 94 & $42.8 \pm 2.6(39-51)$ & 41 \\
\hline Other $(n=12)$ & & $43.5 \pm 4.0(39-52)$ & \\
\hline Men & 5 & $46.8 \pm 4.3(41-52)$ & NA \\
\hline Women & 7 & $41.1 \pm 1.3(39-43)$ & 41 \\
\hline
\end{tabular}

NA: not available; SD: standard deviation

Table II. Comparison of the mean femoral head diameters of the three main races using independent $t$-test.

\begin{tabular}{lcc}
\hline Variable & Femoral head diameter $(\mathbf{m m})^{*}$ & p-value \\
\hline Ethnicity & & \\
Chinese & $45.2 \pm 3.1$ & - \\
Indian & $44.4 \pm 3.3$ & - \\
Malay & $44.2 \pm 3.0$ & - \\
Comparison & - & $0.008^{+}$ \\
Chinese vs. Indian & - & $0.001^{+}$ \\
Chinese vs. Malay & - & 0.55 \\
Malay vs. Indian & - & \\
\hline
\end{tabular}

*Data is presented as mean \pm standard deviation. ${ }^{\dagger} p<0.05$ was considered statistically significant.

The distribution of femoral head diameters according to gender is shown in Figs. 1 and 2. The most common femoral head diameter among women was $44 \mathrm{~mm}(\mathrm{n}=119$; Fig. 1), while that for men was $48 \mathrm{~mm}(\mathrm{n}=61$; Fig. 2). In our cohort of Malaysian patients, $20.7 \%$ of women and $79.1 \%$ of men had femoral head diameters $\geq 46 \mathrm{~mm}$. Conversely, $68.0 \%$ of Malaysian women and $15.6 \%$ of Malaysian men had femoral head diameters $\leq 44 \mathrm{~mm}$. In our cohort, a significant number of patients, especially women, had very small femoral head diameters of $<40 \mathrm{~mm}-2.7 \%$ $(18 / 663)$ of women and $0.4 \%$ (1/282) of men (Figs. 1 \& 2).

Comparing the gender-based mean femoral head diameters in our study against previously published studies in the literature (Table III), we found that the mean femoral head diameter among the Malaysian patients in our study was smaller than that of Caucasians, even without taking thickness of the articular surface (average $44.9 \mathrm{~mm}$ ) into account. ${ }^{(4-6)}$ Independent $t$-test found the difference between the femoral head diameters of Malaysian and Caucasian populations to be significant $(p<0.005)$.

\section{DISCUSSION}

Malaysia is a multiracial country, with Malays, Chinese and Indians respectively making up $65 \%, 26 \%$ and $8 \%$ of the population. ${ }^{(8,9)}$ However, the racial distribution of patients in our study did not correspond to that of our national population. As our

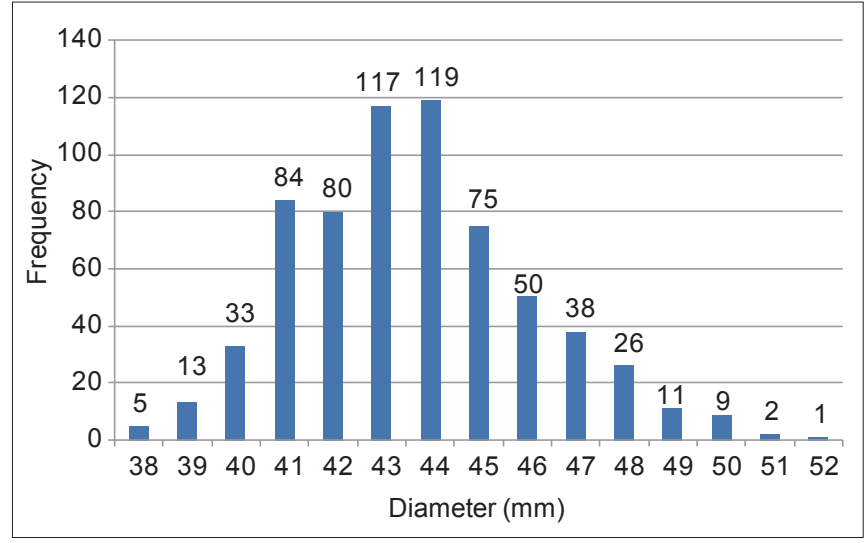

Fig. 1 Graph shows the distribution of femoral head diameters among Malaysian women $(n=663)$.

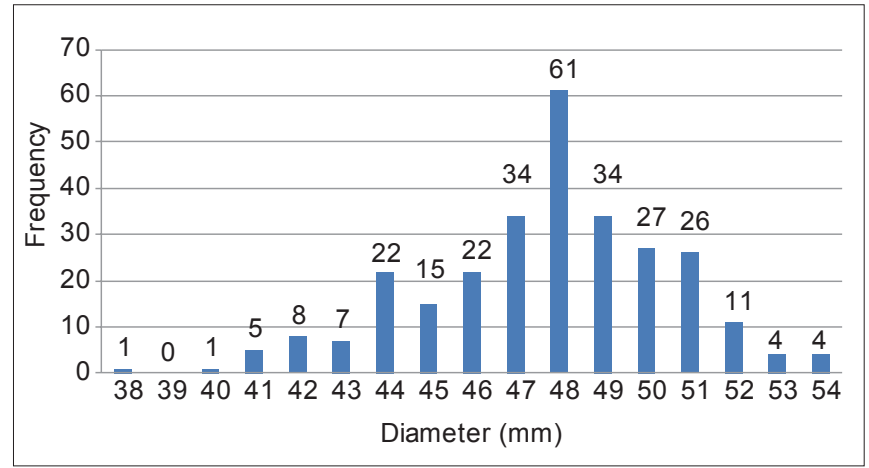

Fig. 2 Graph shows the distribution of femoral head diameters among Malaysian men $(n=282)$

study population was mainly urban, this may have accounted for the higher proportion of Chinese in our cohort. Notwithstanding this anomaly, the multiracial nature of Malaysia's population allowed us to study the surgical morphometry of the femoral head diameter of patients from the three most dominant racial groups in Asia (i.e. Chinese, Indian and Malay). Our study population was predominantly female, and it is possible that the nature of the recruitment of our cohort - which primarily included patients with fractures of the neck of the femur - was a factor. One of the underlying causes of such fractures is osteoporosis, a condition known to be predominant among women. ${ }^{(10)}$

We determined the mean, range and mode of the femoral head diameter for each of the three major races (i.e. Malay, Chinese and Indian) in Malaysia. In our study, the mean femoral head size among Malay patients was $44.2 \pm 3.0 \mathrm{~mm}$ $(43.0 \pm 2.0 \mathrm{~mm}$ in women; $47.4 \pm 3.1 \mathrm{~mm}$ in men), while that among Indians was $44.4 \pm 3.3 \mathrm{~mm}(42.8 \pm 2.6 \mathrm{~mm}$ in women; $47.0 \pm 2.7 \mathrm{~mm}$ in men). In contrast, the mean femoral head size among our Chinese patients was $45.2 \pm 3.1 \mathrm{~mm}(44.0 \pm 2.4 \mathrm{~mm}$ in women; $48.0 \pm 2.7 \mathrm{~mm}$ in men).

In comparison with previous studies ${ }^{(4-6)}$ in the literature, our study showed that the femoral head diameter of Malaysians was significantly smaller than that in Caucasian populations $(p<0.005$; Table III). This observation is expected, especially in view of the differences in physical size and height between Asian and Caucasian populations. ${ }^{(11)}$ The difference in the femoral head diameters of these populations would be even greater if the thickness of the 
Table III. Comparison of the mean femoral head diameter in our study with that found in previous studies using independent $t$-test. ${ }^{(4-6)}$

\begin{tabular}{|c|c|c|c|c|c|c|c|}
\hline Study (year) & $\begin{array}{c}\text { No. of } \\
\text { patients }\end{array}$ & $\begin{array}{l}\text { Study } \\
\text { population }\end{array}$ & $\begin{array}{c}\text { Mean age of } \\
\text { patients (yrs) }\end{array}$ & $\begin{array}{c}\text { Male to female } \\
\text { ratio }\end{array}$ & $\begin{array}{c}\text { Femoral head } \\
\text { diameter }(\mathrm{mm})\end{array}$ & $\begin{array}{l}\text { Type of } \\
\text { measurement }\end{array}$ & p-value \\
\hline Noble et al(4) $(1988)$ & 200 & Caucasian & 79.9 & NA & $46.1 \pm 4.8$ & Dry cadaveric* & $<0.005$ \\
\hline \multirow[t]{2}{*}{ Hoaglund and Low(5) (1980) } & 121 & Caucasian & NA & $103: 18$ & 46 (men), 43 (women) & Dry cadaveric* & NA \\
\hline & 91 & Chinese & NA & $74: 17$ & 45 (men), 40 (women) & Dry cadaveric* & NA \\
\hline Massin et $\mathrm{al}^{(6)}(2000)$ & 200 & Caucasian & 67 & $69: 131$ & $45.6 \pm 4.2$ & Radiological* & $<0.005$ \\
\hline Present study (2014) & 945 & Asian & 75.2 & $282: 663$ & $44.9 \pm 3.2$ & Intraoperative ${ }^{+}$ & \\
\hline
\end{tabular}

*Without intact cartilage coverage. With intact cartilage coverage. NA: not available

articular cartilage were to be taken into account, given that articular cartilage has been shown to contribute approximately $3 \mathrm{~mm}$ to the femoral head diameter. ${ }^{(12)}$ However, we found that the thickness of the cartilage was not taken into account during the measurement of femoral head diameter in most earlier studies. ${ }^{(4-6)}$ For instance, studies by Noble et $\mathrm{al}^{(4)}$ and Hoaglund and Low ${ }^{(5)}$ assessed dry cadaveric bone without an intact articular surface, while Massin et $\mathrm{a}^{(6)}$ mainly assessed the femoral head size radiologically.

Hoaglund and Low, in their dry cadaveric study, also evaluated the Hong Kong Chinese population. ${ }^{(5)}$ Comparing according to gender, and on adding an average cartilage thickness of $3 \mathrm{~mm}$, the Hong Kong Chinese population $(43 \mathrm{~mm}$ in women; $48 \mathrm{~mm}$ in men) was found to have a similar femoral head diameter as our Malaysian Chinese population $(44.0 \mathrm{~mm}$ in women; $48.0 \mathrm{~mm}$ in men).

Our findings on the femoral head diameter of Malaysian patients are particularly relevant and useful for surgical procedures such as hip resurfacing surgery (HRS) and total hip replacement (THR) in the local population. For instance, in recent years in arthroplasty, HRS using metal-on-metal bearings has gained popularity. ${ }^{(1-2)}$ Implant size in HRS is indirectly dictated by femoral head size, and in order to perform HRS, a minimum femoral head/acetabular size of $46 \mathrm{~mm}$ is required to accommodate the smallest femoral head component of $36 \mathrm{~mm} .{ }^{(13)}$ Because of this precondition and in light of our findings (Figs. 1 \& 2), we postulate that nearly $80 \%$ of Malaysian women and $21 \%$ of Malaysian men may be unsuitable for HRS. However, THR surgery using metal-on-polyethylene implants requires only a minimum acetabular cup size of $44 \mathrm{~mm}$ for the use of standard 28-mm metal head implants, so as to have a minimum polyethylene thickness of $8 \mathrm{~mm}$ available on each side. Our findings suggest that all patients in our study would be able to undergo THR surgery using the standard 28-mm femoral head implants with a minimum acetabular cup size of $44 \mathrm{~mm}$, provided that the acetabular reaming removes at least $3 \mathrm{~mm}$ of the articular cartilage/subchondral bone (Figs. 1 \& 2). However, proper preoperative templating would still be mandatory in the Malaysian population, so that the size of the implants can be determined before surgery. This would allow for time to arrange for alternative options should the femoral head/acetabular size be too small for standard HRS or THR procedures or implants. Our findings are also useful for hospital inventory and storage of hip implants for procedures such as hemiarthroplasty, and are relevant for manufacturers involved in the production and inventory of implants for Asian populations.
To the best of our knowledge, our study is the largest case series to date that has examined femoral head diameters among Malaysian patients. Even so, a limitation of our study is that our study cohort may not be representative of the general Malaysian population due to differences seen between the distribution of patients in our study and that of the national population, with regard to gender and race. For this reason, the extrapolation of our results to all Malaysians may be limited.

In conclusion, we found the mean femoral head diameter of a multiracial Asian population from Malaysia to be $44.9 \pm 3.2$ (range 38-54) mm. In our study, men had significantly larger femoral head diameters than women, and Chinese patients had significantly larger femoral head diameters than our Indian and Malay patients.

\section{REFERENCES}

1. National Joint Registry. National Joint Registry for England, Wales and Northern Ireland - 10th Annual Report 2013. In: National Joint Registry Annual Reports [online]. Available at: http://www.njrcentre.org.uk/njrcentre/ Portals/0/Documents/England/Reports/10th_annual_report/NJR\%20 10th\%20Annual\%20Report\%202013\%20B.pdf. Accessed July 10, 2014.

2. American Joint Replacement Registry. American Joint Replacement Registry Fall 2013 Update. In: AJRR Home [online]. Available at: http://teamwork. aaos.org/ajrr/AJRR\%20Documents/AJRR\%20Fall\%202013_F11062013. pdf. Accessed July 10, 2014.

3. Harkess JW. Arthroplasty of hip. In: Canale ST, Beatty JH, eds. Campbell's operative orthopaedics. 10th ed. Philadelphia: Mosby Elsevier, 2007: 348-371.

4. Noble PC, Alexander JW, Lindahl LJ, et al. The anatomic basis of femoral componnet design. Clin Orthop Relat Res 1988; 235:148-65.

5. Hoaglund FT, Low WD. Anatomy of the femoral neck and head, with comparative data from Caucasians and Hong Kong Chinese. Clin Orthop Relat Res 1980; 152:10-6.

6. Massin P, Geais L, Astoin E, Simondi M, Lavaste F. The anatomic basis for the concept of lateralized femoral stems: a frontal plane radiographic study of the proximal femur. J Arthroplasty 2000; 15:93-101.

7. Chauhan R, Paul S, Dhaon BK. Anatomical parameters of North Indian hip joints: cadaveric study. J Anat Soc India 2002; 51:39-42.

8. Department of Statistics Malaysia. Census of Population and Housing Malaysia 2000 [online]. Available at: http://www.statistics.gov.my/eng/ index.php. Accessed September 5, 2008.

9. Department of Statistics Malaysia. Population (Updated 5 September 2008) [online]. Available at: http://www.statistics.gov.my/eng/index.php. Accessed September 5, 2008.

10. Maggi S, Kelsey JL, Litvak J, Keyse SP. Incidence of hip fractures in the elderly: a cross-national analysis. Osteoporos Int 1991; 1:232-41.

11. Zhang YY, Liu PY, Lu Y, et al. Race and sex differences and contribution of height: a study on bone size in healthy Caucasians and Chinese. Am J Hum Biol 2005; 17:568-75.

12. Wyler A, Bousson V, Bergot C, et al. Hyaline cartilage thickness in radiographically normal cadaveric hips: comparison of spiral CT arthrographic and macroscopic measurements. Radiology 2007; 242:441-9.

13. Smith \& Nephew. Birmingham Hip Resurfacing System [online]. Available at: http://www.smith-nephew.com/documents/nl-bhr-surgicaltechnique. pdf. Accessed July 10, 2014. 